\title{
Phytochemical Analysis, Antibacterial and Antioxidant Activity of the Leave Extracts of Ruta Chalepensis
}

\author{
Ketema Alemayehu* Destaw Engidaw Seid Mustofa \\ Department of Chemistry, College of Natural and Computational Science, Wolaita Sodo University, Wolaita \\ Sodo, Ethiopia
}

\begin{abstract}
Rue (Ruta chalepensis) commonly known as rue, is traditionally used in Ethiopia for the treatment of a variety of diseases. Therefore this study conducted to investigate phytochemical constituents, antibacterial and antioxidant activity of the leave extracts of Ruta chalepensis. The phytochemical screening tests were conducted as per the standard procedure to identify the classes of compounds present in the leave extract of Ruta chalepensis. In vitro antibacterial activities of crude extracts were evaluated via disc diffusion method while antioxidant activities of extracts were determined by DPPH assay, the phosphomolybdenum method and total flavonoid contents were determined as per of the standard procedures. Phytochemical screening of leave extracts of Ruta chalepensis revealed the presence of secondary metabolites. The methanol extract had the greatest DPPH scavenging $(93.851 \pm 0.148 \%)$ and total antioxidant $(1.63 \pm 0.19 \mathrm{mg}$ AAE/g of dried extract $)$ activities. Ethyl acetate extract showed the growth suppression of Bacillus cereus and Escherichia coli and methanol extract showed growth suppression of Bacillus cereus and Staphylococcus aureus with minimum inhibition concentration $50 \mathrm{mg} / \mathrm{mL}$. The antibacterial activities of the extracts were compared with a commercially available antibiotic (chloramphenicol) and showed moderate antibacterial activities, with inhibition zones ranging between $18-28 \mathrm{~mm}$. Therefore the solvent extracts of Ruta chalepensis revealed the presence of important secondary metabolites, antibacterial and antioxidant activities.
\end{abstract}

Keywords: Antimicrobial activity, antioxidant activity, phytochemical profile, Ruta chalepensis

DOI: $10.7176 / \mathrm{CMR} / 11-6-01$

Publication date: August 31st 2019

\section{Introduction}

Medicinal plants were consistently used for health care and serve as the bases for the emergence of modern medicine. Thus, plants form an integral part of life in many indigenous African communities as a readily and cheaply accessible alternative to allopathic medicines. Due to either limited availability or affordability of pharmaceutical medicines, about $80 \%$ of the rural population in Sub-Saharan Africa (SSA) depends on traditional herbal remedies for primary health care (PHC) and veterinary use [1].

Because of the significant require for primary health care throughout the world, and WHO's recommendations that traditional practitioners be utilized as a component part of this primary health care team, there is a need to review studies and projects that have used traditional practitioners in some aspects of promoting community health.

Multiple drug resistance has developed due to the indiscriminate use of antimicrobials and reemergence of diseases; adverse drug reactions and the high costs of antimicrobials have been key contributors to ineffective management of infectious diseases in many developing countries. Natural products of higher plants may give a new source of antimicrobial agents with possibly novel mechanisms of action [2].

Phytochemicals are compounds that have protective or disease preventive properties naturally produced by plants. They are usually called plant secondary metabolites and are classified into major groups such as alkaloids, anthraquinones, coumarins, flavonoids, glycosides, saponins, steroids, tannins, and terpenes, etc. The concentration and type of phytochemicals present vary in different parts of a plant. The therapeutic value of any plant thus lies in the quality and quantity of the secondary metabolites or active principles. Some compounds obtained from natural sources have also been used as leads or precursors that can be modified synthetically to improve their therapeutic activities [3].

The leaves and young stems of Ruta chalpensis have been reported to contain alkaloids, flavonoids, phenols, amino acids, furanocoumarins, and saponins. In addition, the phytochemical screening of the aerial parts of $R$. chalepensiswas conducted for the determination of alkaloids, cardiac glycosides, flavonoids, tannins, coumarins, anthraquinones, saponins, volatile oil, volatile bases, cynogenic glycosides, glucosinolates, sterols and/or triterpenes [4]. Ruta is also one of the most frequently used plants for medicinal purposes. The characteristic odour of the plant and volatile oil is due to methyl n-nonyl ketone [5]. Traditionally, Ruta is also used as a remedy for many inflammatory diseases [6].

The recent bioassay investigations on Ruta chalpensis described anti-bacterial and antioxidant activities, this study provides further information in documenting knowledge for potential researchers in the area of phytochemistry. The objective of the research was to investigate phytochemical constituents, antibacterial and 
antioxidant activity of the leave extracts of Ruta chalpensis.

\section{Materials and methods}

Chemicals, reagents, and standards

Methanol, Acetone, Hexane, Ethyl acetate, distilled water, 1\% Lead acetate, Ferric chloride, Ammonia, Iodine, Hydrochloric acid, Mayer's reagent, Sulphuric acid, Acetic acid glacial, Ethanol, Chloroform, Hydrochloric acid, Picric acid, DMSO, chloroamphinicol, Potassium iodide, and Benzene.

\section{Instruments and Apparatus}

Spectrophotometer, Digital analytical Balance, Beaker, Metal stand with clamps, Bottle, Test tube, Separatory funnel, Spatula, Mortar and pestle, Volumetric flask, Erlenmeyer flask, Wash glass, Pipette, Stir rod, Measuring cylinder, Glass plate, Burette, Petri-dish, Hose, Whatman filter paper.

Sample preparation and extraction:

The leaves used for investigation were purchased from a local retailers. The sample was identified by botanist and voucher specimen (088679) has been deposited at the flora of Ethiopia at the herbarium of Ethiopia at Addis Ababa University. The leaves of the plant ware chopped into small pieces; air dried at room temperature $\left(25^{\circ} \mathrm{C}\right)$ under the shade and pulverized using a laboratory mill yielding 300-500g. The fine powders were separately soaked in different solvents (methanol, acetone, hexane and ethyl acetate) for 4 days at room temperature to produce extracts. The solvents are chosen depending on their polarity deference. The filtrate was dried by using a rotary evaporator at a temperature of about $40-45^{\circ} \mathrm{C}$. The dried extracts ware put in the deep freezer until needed for the experiment. Phytochemical Screening

Phytochemical screening of Ruta chalpensis leaves was performed according to the standard procedure Preliminary phytochemical screening of different secondary metabolites of leaves extract of Ruta chalpensis solvent extracts was qualitatively carried out with the following procedures [7-8].

The small amount of extracted sample was screened qualitatively for the presence of alkaloids, phenols, steroids, terpenoids, flavonoids, saponins, tannins, anthraquinones, and cardiac glycoside. Further, the sample was extracted for the quantitative determination of flavonoid.

Tests for saponins: $0.5 \mathrm{~mL}$ of each solvent extracts were mixed separately with $10 \mathrm{~mL}$ of distilled water and then agitated (shaken) in a graduated cylinder vigorously for 15 minutes. The formation of foam indicates the presence of saponins.

Tests for tannins: $0.5 \mathrm{~mL}$ of each solvent extracts were added separately to 2 drops of $1 \%$ lead acetate. A yellowish precipitate indicated the presence of tannins.

Tests for Phenols:

Ferric chloride test: $1 \mathrm{~mL}$ of each solvent extracts were treated separately with 2 drops of ferric chloride solution. The formation of bluish black color indicates the presence of phenols.

Tests for anthraquinones:

Borntreger's test: $0.5 \mathrm{~mL}$ of each solvent extracts were shaken separately with $4 \mathrm{~mL}$ of Benzene. These were filtered and $1 \mathrm{~mL}$ of $10 \%$ ammonia solution was added to the filtrate. The mixture was shaken and the presence of violet colour in the lower phase indicated the presence of free hydroxyl anthraquinones.

Tests for alkaloids:

Iodine test: 2 drops of dilute iodine solution were added to $0.5 \mathrm{~mL}$ of each solvent extracts separately. The blue color was appeared and disappeared on boiling and reappeared on cooling indicates the presence of alkaloids.

Wagner's test: $1 \mathrm{~mL}$ of each solvent extracts were mixed separately with $0.5 \mathrm{~mL}$ of $1 \% \mathrm{HCl}$ and heated gently. Wagner's reagent was then added to the mixture. The turbidity of the resulting precipitate was taken as evidence for the presence of alkaloids.

Mayer's test: $0.5 \mathrm{~mL}$ of each solvent extracts were evaporated separately to dryness and the residue was heated on a boiling water bath with $2 \mathrm{~mL}$ of $2 \mathrm{~N} \mathrm{HCl}$. After cooling, the mixture was filtered and treated with 2 drops of Mayer's reagent. The presence of turbidity or precipitate was taken as positive for alkaloids.

Tests for glycosides:

Salkowski's test: $1 \mathrm{~mL}$ of each solvent extracts were mixed separately with $0.5 \mathrm{~mL}$ of chloroform. Then $0.5 \mathrm{~mL}$ of concentrated $\mathrm{H}_{2} \mathrm{SO}_{4}$ was added in each carefully and shaken gently. A reddish brown colour indicated the presence of glycosides.

Tests for flavonoids:

Shinoda test: $0.5 \mathrm{~mL}$ of each solvent extracts were mixed separately with few fragments of magnesium ribbon and concentrated $\mathrm{HCl}$ was added dropwise. The pink scarlet colour appeared after a few minutes which indicated the presence of flavonoids.

Alkaline test: $0.5 \mathrm{~mL}$ of each solvent extracts were treated separately with 2 drops of sodium hydroxide solution. The formation of intense yellow color indicates which became colorless on the addition of dilute hydrochloric acid which indicated the presence of flavonoids.

Tests for Steroids: $0.5 \mathrm{~mL}$ of each solvent extracts were dissolved separately in $6 \mathrm{~mL}$ of chloroform and an equal 
volume of concentrated sulphuric acid was added by sides of the test tube. The upper layer turns red and the sulphuric acid layer was showed yellow with green fluorescence. This indicates the presence of steroids.

Tests for terpenoids: $1 \mathrm{~mL}$ of each solvent extracts were added separately to $1 \mathrm{~mL}$ of acetic anhydride and $1 \mathrm{~mL}$ of concentrated $\mathrm{H}_{2} \mathrm{SO}_{4}$. Formations of blue-green rings indicate the presence of terpenoids.

Determination of total flavonoid content (TFC)

Total flavonoid was estimated using the method of Ebrahimzadeh et al., [9]. The extract $(1 \mathrm{~mL}, 1 \mathrm{mg} / \mathrm{mL}) \mathrm{was}$ diluted with $1.25 \mathrm{~mL}$ distilled water and $75 \mu \mathrm{L} 5 \% \mathrm{NaNO}_{2}$ was added to the mixture. After $6 \mathrm{~min}, 150 \mu \mathrm{L} 10 \%$ $\mathrm{AlCl}_{3}$ was added and after another $5 \mathrm{~min}, 1 \mathrm{~mL} 1 \mathrm{M} \mathrm{NaOH}$ was added to the mixture. Immediately, the absorbance of the mixture, pink in color, was determined at $510 \mathrm{~nm}$ versus prepared water blank. A standard curve was prepared using $5-120 \mu \mathrm{g} / \mathrm{mL}$ of catechin. Results were expressed as milligram of catechin equivalents per milligram of dry extract of the plant extract. $\left(\mathrm{Y}=0.022 \mathrm{x}+0.041, \mathrm{R}^{2}=0.99, \mathrm{P}<0.001\right)$.

\section{Antioxidant activity tests}

DPPH assay:

The DPPH free radical scavenging activity of the extracts of leaves of Ruta chalpensis was assayed according to the method of Szollosi et al., [10], with slight modification. Different concentrations (50 to $1000 \mu \mathrm{g} / \mathrm{mL}$ ) of the extracts were taken in different test tubes. Freshly prepared DPPH solution $(2 \mathrm{~mL}, 0.006 \%$, w/v $)$ was prepared in methanol was added in each of the test tubes containing $1 \mathrm{~mL}$ of the extract. The reaction mixture and the reference standards (ascorbic acid and BHT) were vortexed and left to stand at room temperature in the dark for $30 \mathrm{~min}$. The absorbance of the resulting solution was then taken at $520 \mathrm{~nm}$. Methanol was used as blank. The ability to scavenge the DPPH radical was calculated using the following equation:

$$
\text { DPPH scavenged }(\%)=\frac{(A c-A s)}{A c} \times 100
$$

Where Ac is the absorbance of the control and As is the absorbance in the presence of the sample of the extracts. Total antioxidant using phosphomolybdenum method

The total antioxidant activities of the crude extracts were evaluated by the phosphomolybdenum method reported by Prieto et al., [11], with slight modification. $0.3 \mathrm{~mL}$ plant extract $(0.5$ and $1 \mathrm{mg} / \mathrm{mL})$ was mixed with $3 \mathrm{~mL}$ of reagent solution ( $0.6 \mathrm{M}$ sulphuric acid, $28 \mathrm{mM}$ sodium phosphate and $4 \mathrm{mM}$ ammonium molybdate). The samples were incubated at $95{ }^{\circ} \mathrm{C}$ for $90 \mathrm{~min}$, was cooled to room temperature and absorbance was measured at $695 \mathrm{~nm} .3$ $\mathrm{mL}$ of methanol was used as a blank. The total antioxidant activity was expressed as milligram ascorbic acid equivalent/gram of dried extract ( $\mathrm{mg} \mathrm{AAE} / \mathrm{g})\left(\mathrm{y}=0.321 \mathrm{x}+0.019 ; \mathrm{R}^{2}=0.996, \mathrm{P}<0.001\right)$ based on the calibration curve.

\section{Evaluation of antibacterial activity \\ Disc diffusion method}

Antimicrobial activities of methanol, acetone, hexane and ethyl acetate extracts of Ruta chalpensis were determined by disc diffusion [12] and broth dilution methods. Culture media of mannitol salt agar for staphylococcus aureus, salmonella shigella agar for Salmonella typhi, ECD agar for E.coli and Bacillus cereus agar for bacillus cereus were prepared and poured into the plates. The depth of the medium should be $4 \mathrm{~mm}$. Three to four similar colonies of pure cultures were inoculated with dextrose broth, incubated at $37{ }^{\circ} \mathrm{C}$ for $2-8 \mathrm{~h}$ and the size of the inoculum was adjusted to yield uniform suspension containing 105-106 cells/mL (McFarland's standard). The agar surfaces of the plates were swabbed with test culture in three directions turning the plates to $60^{\circ}$ between each swabbing. Confluent growth is desirable for an accurate results. The sterile discs were $(6 \mathrm{~mm}$; Himedia) used for the loading crude plant extracts. Four different concentrations were prepared (100, 50, 25 and $12.5 \mathrm{mg} / \mathrm{mL}$ ) and loaded in an appropriate disc. The impregnated discs were incubated at $37^{\circ} \mathrm{C}$ for an hour. The dried discs were placed over the surface of the swabbed medium with equal distance to avoid the overlapping of the zone of inhibition. Pre-diffusion time was given to the swabbed plates in refrigerator condition for 5 min. The plates were incubated at $37{ }^{\circ} \mathrm{C}$ for $16-18 \mathrm{~h}$ during which the activity was evidenced by the presence of a zone of inhibition surrounding the discs. Each experiment was done in triplicate. A panel of antibiotics was used against each microbial strain and compared with the standard of chloramphenicol control standard. A filter paper disc impregnated with Ciprofloxacin prepared in DMSO $(50 \mathrm{mg} / \mathrm{mL})$ was used as positive control and DMSO was used as a negative control. The inhibition zone diameters were measured in millimeters.

\section{Broth Dilution Method}

The broth dilution method was used to determine the minimum inhibitory concentration (MIC) of the extracts in Dextrose Broth (Himedia-M 033) as specified by the National Committee for Clinical Laboratory Standard. A total of $10 \mathrm{~mL}$ of the broth was dispensed into a separate test tube and was sterilized at $121{ }^{\circ} \mathrm{C}$ for 15 min and then allowed to cool. Two-fold serial dilutions of the extracts in the broth were made from the stock concentration of the extracts to obtain $1.563-100 \mathrm{mg} / \mathrm{mL}$ for the extracts. About $0.1 \mathrm{~mL}$ of the standardized inoculums of the microbes were inoculated into the different concentrations of the extracts in the broth. The test tubes of the broth were incubated at $37{ }^{\circ} \mathrm{C}$ for $24 \mathrm{~h}$ and observed for turbidity. The lowest concentration that showed no turbidity in 
the test tube was recorded as the MIC. And compare with the standard of chloramphenicol control standard.

\section{RESULTS}

phytochemical screening

The preliminary phytochemical qualitative analysis of methanol, acetone, n-hexane and ethyl acetate extracts of Ruta chalpensis is summarized in Table 1.

Table 1 Qualitative phytochemical analysis of leaves extracts of Ruta chalpensis

\begin{tabular}{|c|c|c|c|c|c|}
\hline No. & $\begin{array}{l}\text { Phytochemical } \\
\text { Constituents }\end{array}$ & Methanol extract & Ethyl acetate & Acetone extract & n-hexane extract \\
\hline 1 & Alkaloids & + & - & - & - \\
\hline 2 & Flavonoids & + & - & - & + \\
\hline 3 & Steroids & - & + & + & - \\
\hline 4 & Terpenoids & + & + & + & + \\
\hline 5 & Cardiac glycosides & - & - & - & - \\
\hline 6 & Phenols & + & - & - & - \\
\hline 7 & Saponins & + & + & + & - \\
\hline 8 & Tannins & + & - & - & - \\
\hline 9 & Anthraquinones: & + & - & + & + \\
\hline
\end{tabular}

\section{(+) Presence, (-) Absence}

The results showed the presence of alkaloids, flavonoids, anthraquinones, tannins, terpenoids, phenols and saponins in methanol extract, steroids, terpenoids and saponins were presence in ethyl acetate extract, steroids, terpenoids, saponins and anthraquinones were presence in acetone extract and flaonoids, terpenoids and anthraquinones were presence in $\mathrm{n}$-hexane. Phytochemical screening test actually helps in isolating and characterizing the chemical constituents present in the plant extracts and the knowledge of the chemical constituents of plants is desirable to understand herbal drugs and their preparations and finally in discovering the actual value of folkloric remedies [13]. Phytochemicals such as alkaloids, flavonoids, steroids, terpenoids, cardiac glycosides, phenols, saponins and tannins present in different extracts exhibit a number of biological activities and protect from most of the chronic diseases $[14,15]$. and often used as medications and recreational drugs [16].

\section{DPPH scavenging}

The degree of discoloration of violet colour of DPPH radical, as it gets reduced, indicates the radical scavenging potential of the antioxidant [17].

Table 2 DPPH radical scavenging activity (\%) of leaves extracts of Ruta chalpensis and controls (L-ascorbic acid and BHT).

\begin{tabular}{|l|l|l|l|l|l|l|}
\hline \multirow{2}{*}{$\begin{array}{l}\text { Concentration } \\
(\mathrm{mg} / \mathrm{mL})\end{array}$} & \multicolumn{6}{|l|}{ Radical Scavenging Concentration Values (\%) } \\
\cline { 2 - 7 } & Methanol & Acetone & $\begin{array}{l}\text { Ethyl } \\
\text { acetate }\end{array}$ & n-hexane & Ascorbic acid & BHT \\
\hline 50 & $37.678 \pm 1.67$ & $28.505 \pm 0.59$ & $40.809 \pm 2.79$ & $31.809 \pm 0.15$ & $97.259 \pm 0.049$ & $74.454 \pm 0.049$ \\
\hline 100 & $42.876 \pm 0.93$ & $32.416 \pm 2.36$ & $40.525 \pm 0.26$ & $35.578 \pm 2.45$ & $97.334 \pm 0.011$ & $84.417 \pm 0.075$ \\
\hline 250 & $48.270 \pm 1.15$ & $45.534 \pm 0.93$ & $48.678 \pm 0.10$ & $43.836 \pm 1.38$ & $97.302 \pm 0.058$ & $86.472 \pm 0.024$ \\
\hline 500 & $63.207 \pm 2.75$ & $59.45 \pm 0.67$ & $65.508 \pm 0.85$ & $50.101 \pm 1.36$ & $97.277 \pm 0.058$ & $91.805 \pm 4.604$ \\
\hline 1000 & $93.851 \pm 0.15$ & $78.937 \pm 0.96$ & $76.590 \pm 0.13$ & $64.499 \pm 0.68$ & $97.343 \pm 0.089$ & $94.687 \pm 0.016$ \\
\hline
\end{tabular}

Values are average of triplicate measurements (mean \pm SD)

The DPPH radical scavenging effects of extracts of Ruta chalpensis in different solvent systems showed in table 2. At the concentration of $1000 \mu \mathrm{g} / \mathrm{mL}$ used, the scavenging effect of L-ascorbic acid, BHT, and Ruta chalpensis extracts, on the DPPH radical decreased in the order of L-ascorbic acid $>$ BHT $>$ methanol $>$ acetone $>$ ethyl acetate $>$ n-hexane, which were $(97.30 \pm 3.50) \%,>(94.70 \pm 14.60) \%,>(93.851 \pm 0.148) \%>$ $(78.937 \pm 0.961) \%>(76.590 \pm 0.131) \%$, and $64.499 \pm 0.679$ respectively.

Determination of total flavonoid content (TFC)

Table 3:-Total flavonoid content of various solvent extracts of Ruta chalpensis

\begin{tabular}{|l|l|}
\hline Solvent extract & TFC $(\mathrm{mg} \mathrm{CE} / \mathrm{g})$ \\
\hline Acetone & $3.427 \pm 0.750$ \\
\hline Methanol & $1.125 \pm 0.053$ \\
\hline Ethyl acetate & $2.127 \pm 0.221$ \\
\hline n-hexane & $1.667 \pm 0.066$ \\
\hline
\end{tabular}

Values are expressed as mean $\pm \mathrm{SD}(\mathrm{n}=3)$ from triplicate experiments. Means with different letters in a column were significantly different at the level of $\mathrm{P}<0.05$.

The TFC Table 3 followed the order: acetone $>$ ethyl acetate $>$ n-hexane $>$ methanol. There was significant difference $(\mathrm{P}<0.05)$ in TFC among methanol, acetone, ethyl acetate and n-hexane. 
Anti-microbial activities of the crude extracts

Table 4: Antibacterial effects of leaves of Ruta chalepensis

\begin{tabular}{|l|l|l|l|l|l|}
\hline \multirow{2}{*}{ Name of Microorganism } & \multicolumn{5}{|c|}{ Zone of inhibition(in mm) } \\
\cline { 2 - 7 } & Methanol & Acetone & Ethyl acetate & n-hexane & chloroaphenol \\
\hline B. cereus & $15.33 \pm 1.53$ & $15.67 \pm 1.53$ & $17.00 \pm 2.65$ & $15.67 \pm 2.52$ & $18-30$ \\
\hline S. aureus & $14.33 \pm 2.08$ & $15.33 \pm 1.53$ & $14.67 \pm 2.08$ & $13.33 \pm 1.53$ & $18-30$ \\
\hline S. typhi & $12.67 \pm 1.53$ & $11.33 \pm 1.53$ & $14.33 \pm 2.08$ & $12.33 \pm 2.08$ & $18-30$ \\
\hline E. coli & $11.00 \pm 2.65$ & $11.67 \pm 1.53$ & $15.67 \pm 2.52$ & $12.67 \pm 2.52$ & $18-30$ \\
\hline
\end{tabular}

Table 5:- MIC value of leaves extracts of Ruta chalepensis against tested bacterial strain Methanol extract

\begin{tabular}{|l|l|l|l|l|l|l|l|l|l|}
\hline & \multicolumn{9}{|c|}{ Concentration of extract (in mg/mL) } \\
\cline { 2 - 12 } Microorganism & 100 & 50 & 25 & 12.5 & 6.25 & 3.13 & 1.56 & 0.78 & MIC \\
\hline B. cereus & + & + & - & - & - & - & - & - & 25 \\
\hline S. aureus & + & + & - & - & - & - & - & - & 25 \\
\hline S. typhi & + & + & - & - & - & - & - & - & 25 \\
\hline E. coli & + & + & - & - & - & - & - & - & 25 \\
\hline
\end{tabular}

\section{Ethyl Acetate extract}

\begin{tabular}{|l|l|l|l|l|l|l|l|l|l|}
\hline & \multicolumn{8}{|c|}{ Concentration of extract (in $\mathrm{mg} / \mathrm{mL})$} \\
\cline { 2 - 12 } Microorganism & 100 & 50 & 25 & 12.5 & 6.25 & 3.13 & 1.56 & 0.78 & MIC \\
\hline B. cereus & + & + & - & - & - & - & - & - & 25 \\
\hline S. aureus & + & + & - & - & - & - & - & - & 25 \\
\hline S. typhi & + & + & - & - & - & - & - & - & 25 \\
\hline E. coli & + & + & - & - & - & - & - & - & 25 \\
\hline
\end{tabular}

\section{Acetone extract}

\begin{tabular}{|l|l|l|l|l|l|l|l|l|l|}
\hline \multirow{2}{*}{ Microorganism } & \multicolumn{9}{|c|}{ Concentration of extract (in $\mathrm{mg} / \mathrm{mL}$ ) } \\
\cline { 2 - 11 } & 100 & 50 & 25 & 12.50 & 6.25 & 3.13 & 1.56 & 0.78 & MIC \\
\hline B. cereus & + & + & - & - & - & - & - & - & 25 \\
\hline S. aureus & + & + & - & - & - & - & - & - & 25 \\
\hline S. typhi & + & + & - & - & - & - & - & - & 25 \\
\hline E. coli & + & + & - & - & - & - & - & - & 25 \\
\hline
\end{tabular}

n-hexane

\begin{tabular}{|l|l|l|l|l|l|l|l|l|l|}
\hline & \multicolumn{9}{|c|}{ Concentration of extract (in mg/mL) } \\
\cline { 2 - 11 } Microorganism & 100 & 50 & 25 & 12.5 & 6.25 & 3.13 & 1.56 & 0.78 & MIC \\
\hline B. cereus & + & + & - & - & - & - & - & - & 25 \\
\hline S. aureus & + & + & - & - & - & - & - & - & 25 \\
\hline S. typhi & + & + & - & - & - & - & - & - & 25 \\
\hline E. coli & + & + & - & - & - & - & - & - & 25 \\
\hline
\end{tabular}

Table 4 summarizes the results of disc diffusion assays of the crude solvent extracts of Ruta chalpensis. All result showed that the extracts possess antimicrobial activities against the selected microorganisms. The antimicrobial activities of the extracts (methanol, acetone, hexane and ethyl acetate) at different concentrations were screened by the disc diffusion method and the mean value of zone of inhibition was assessed in millimeter diameter. The results are given in the tables- 4 . In the disc diffusion method all extracts showed $\geq 11$ mm mean zone of inhibition, further those microorganisms were tested for MIC by broth dilution technique the results are given in tables- 5 . The result revealed that all extract $25 \mathrm{mg} / \mathrm{mL}$ was obtained as MIC value against all microorganisms. The activity somehow nearer to zones produced by the control antibiotics (chloroaphenol).

\section{DISCUSSION}

Now a days there has been considerable concern in the use of plant material as an alternative drug [18] and many components of plant products have been shown to be specially targeted against resistant pathogenic bacteria [19]. Multidrug resistant strain of many pathogens is a serious threat and makes chemotherapy more difficult. The toxicity of new generation antibiotic drugs discourages their use in treatment. Moreover, the current cost of most of the chemotherapeutic agents is unbearable to the public especially in developing countries [20]. The present work was a pioneer attempt to investigate the phytochemical screening, antimicrobial and antioxidant properties of Ruta chalepensis.

Flavonoids are the polyphenolic compounds in the human diet and are found in all plants. The 
pharmacological effects of flavonoids include CNS activity, cardiotonic, lipid lowering, antiulcer, hepatoprotective, anti-inflammatory, antineoplastic, antimicrobial, antioxidant and hypoglycemic activity. Dietary intake of flavonoids containing foods potentially higher in antioxidant activities [21]. Steroids and triterpenoids are pharmalogically active compounds and show the analgesic properties [22]. The steroids also exhibit central nervous system activities. [23] reported the terpenoids to decrease blood sugar level in animals. Cardiac glycosides are also of medicinal importance and used in the treatment of congestive heart failure and cardiac arrhythmia [24]. Phenols and phenolic compounds have tremendous antimicrobial potential. They have been extensively used in disinfections and remained the standards with which other bactericides are compared [25]. They have been reported to exhibit cellular defense mechanism in atherogenesis and cancer. A wide range of phenolic substances show strong antioxidant and antimutagenic activities. As per recent evidences, phenolic compounds could also play an essential health promoting role [26]. Saponins are being promoted commercially as dietary supplements and nutraceuticals in traditional medicine preparations [27]. They also possess hypocholesterolemic and antidiabetic properties [28]. Certain tannins (ellagitannins from Lagerstroemia speciosa) stimulate glucose uptake. They exhibit insulin like activity acting as glucose transport activators of fat cells [29].

The ethyl acetate extract of the leave of Ruta chalepensis possessed comparatively highest antibacterial activities for Bacillus cereus $(17.00 \mathrm{~mm})$ and Escherichia coli $(15.67 \mathrm{~mm})$ and methanol extract possessed highest antioxidant activities (93.851\%). The results of other extracts also showed considerable antimicrobial activity against bacteria in disc diffusion and broth dilution methods. The antimicrobial and antioxidant property of Ruta chalepensis probably associated with the presence of alkaloids, cardiac glycosides, flavonoids, tannins, coumarins, anthraquinones, saponins, volatile oil, volatile bases, cynagenic glycosides, glucosinolates, sterols and/or triterpenes. It is concluded that this study would lead to the establishment of some valuable compound that has to be used to formulate new, different and more potent antimicrobial drugs of natural origin. Further studies are needed to identify the biologically active compounds and to evaluate the efficiency of the compound against pathogenic microorganisms associated with various human diseases.

\section{CONCLUSIONS}

In this work the phytochemical screening, antioxidant and antibacterial activity of the leaves extract of Ruta chalepensis ware investigated. The phytochemical screening of different solvent extracts of leaves of plant of Ruta chalepensis revealed the presence of important secondary metabolites in the leaves. The ethyl acetate extract of the leave of Ruta chalepensis possessed comparatively highest antibacterial activities for Bacillus cereus and Escherichia coli and methanol extract possessed highest antioxidant activities. The presence of phytochemicals can make Ruta chalepensis, a potential drug. However, further study is necessary to quantify, isolate, characterize and other biological activity of the particular compound for drug development.

Acknowledgments:

This work was supported by Wolaita Sodo University, Ethiopia. Department of Chemistry, Hawasa University access to do antibacterial activities, Hawassa College of teachers' education access to do antioxidant activities these all is duly acknowledged.

\section{Conflict of interest}

The authors declare that they have no conflict of interest.

\section{REFERENCES}

1. World Health Organization (WHO): (2002). WHO Traditional Medicine Strategy 2002-2005. World Health Organization, Geneva, WHO/EDM/TRM/ 1. York, pp 256.

2. Runyoro D, Matee M, Olipa N, Joseph C, Mbwambo H. (2006). Screening of Tanzanian medicinal plants for anti-Candida activity. BMC Complement Altern Med; 6(11).

3. Dias DA, Urban S, Roessner U. (2012). A historical overview of natural products in drug discovery. Metabolites; 2:303-336.

4. Cowan, M.M. (1999). Plant products as antimicrobial agents. ClinMicrobiol Rev., 12(4):564- 582.

5. Tanker, N., Ener, B. S, Noyanalpan, N. and Lewis. (1980). Evaluation of the Volatile Oils of Turkish Rutas Regarding Methyl-n-nonylketone J. J. Fac. Pharm. Ankara, 10(61), 59-67.

6. Browner, C.H. (1985). Plants used for reproductive health in Oaxaca Mexico. Econ. Bot., 39(4): 482-504.

7. Kumar, A. Ilavarasn, R. Jayachandran, T. Decaraman, M. Aravindhan, P. Padmanaban, N. and Krishnan, M.R.V. (2009). Phytochemical investigation on a tropical plant. Pak. J. Nutri., 8, 83-85.

8. Ayoola, G.A.,. Coker HAB,. Adesegun SA,. Adepoju-Bello AA,. Obaweya K,. Ezennia E.C and. Atangbayila T.O. (2008). Phytochemical screening and antioxidant activities of some selected medicinal plants used for malaria therapy in South Western Nigeria. Trop. J. Pharm. Res., 7, 1019-1024.

9. Ebrahimzadeh MA, Hosseinimehr SJ, Hamidinia A, and Jafari M. (2008). Antioxidant and free radical scavenging activity of Feijoa sallowiana fruits peel and leaves. Pharmacologyonline., 1: 7-14. 
10. Szollosi R, and Szollosi Varga I. (2002). Total antioxidant power in some species of Labiatae (Adaptation of FRAP method). Acta Biol Szeged. 46:125-127.

11.Prieto P., Pineda M., and Aguilar M., (1999). Spectrophotometric quantitation of antioxidant capacity through the formation of a phosphomolybdenum complex: specific application to the determination of vitamin E. Anal Bio. 269: 337-341.

12.Bauer, A.W., Kirby, W.M.M., Sherris, K.C. \& Truck, M. (1966). Antibiotic susceptibility testing by a standardized single disk method. American Journal of Clinical Pathology. 45, 493.

13. Kantamreddi VSSN; Lakshmi YN; Kasapu VVVS, (2010). Preliminary phytochemical analysis of some important Indian plant species. Int. J. Pharm. Bio Sci. 1(4), 351-358.

14. Sagwan S; Rao DV; Sharma RA, (2010). Phytochemical evaluation and quantification of primary metabolites of Maytenus emarginata (Willd.) Ding Hou J. Chem. Pharm. Res. 2(6):46-50.

15. Rajurkar NS; Gaikwad K, (2012). Evaluation of phytochemicals, antioxidant activity and elemental content of Adiantum capillus veneris leaves J. Chem. Pharm. Res. 4(1), 365-374.

16. Tadzabia K; Maina HM; Maitera ON; Ezekiel JS. (2013). Evaluation of phytochemical and elemental contents of Haematostaphis barteri leaves and stem bark in Hong local government area of Adamawa state, Nigeria $J$. Chem. Pharm. Res. 5(9), 150-156.

17. Singh RP; Murthy KNC; Jayaprakasha GK, (2002). Study on the Antioxidant Activity of Pomegranate ( Punica granatum) Peel and Seed Extract Using in Vitro Models. J. Agric. Food Chem. 50, 81-86.

18. Aqil F, Khan MS, Owais M, Ahmad I. (2005). Effects of certain bioactive plant extracts on clinical isolates of beta-lactamase producing methicillin-resistant Staphylococcus aureus. J of Basic Microbiology 45: 106-114.

19. Nostro A, Cellini L, Di Bartolomeo S et al., (2006). Effects of combining extracts (from propolis or Zingiber officinale) with clarithromycin on Helicobacter pylori. Phytotherapy Research. 20(3): 187-190.

20. Gopalakrishnan Sarala, George Shibumon and Benny PJ. (2010) Antimicrobial effect of Punica granatum on pyogenic bacteria. J of Pharma and Biomed Sci 3(06).

21. Duthie GG; Duthie SJ; Kyle AM. (2000). Plant polyphenols in cancer and heart disease: implications as nutritional antioxidants. Nutr. Res. Rev. 13, 79-106.

22. Malairajan P; Gopalakrishnan G; Narasimhan S; Veni KJK.(2006). Analgesic activity of some Indian medicinal plants. J. Ethnopharmacology 106, 425-428.

23. Luo J; Cheung J; Yevich E, (999). Novel terpenoid-type quinones isolated from Pycnanthu angolensis of potential utility in the treatment of type-2 diabetes. J. Pharmacol. Exptl. Therapy, 288, 529-534.

24. Sharma HL; Sharma KK. (2007). Drug therapy of heart failure. In: Principle of pharmacology, $1 \mathrm{ed}$, Hyderabad, Paras publishers, 314 - 325.

25. Okwu DE, (2001) Evaluation of the chemical compostion of ingigenous spices and flavouring agents. Global J. Pure Appl. Sci. 8, 455-459.

26. Hayashi T; Maruyama H; Hatton K; Hazeki O; Yamasaki K; Tanaka T, (2002) Ellagitannins from Lagerstroemia speciosa as Activators of Glucose Transport in Fat Cells. Planta Med. 68(2), 173-175.

27. Hosseinzadeh H; Nassir AM, Review of Pharmacological Effects of Glycyrrhiza sp. and its Bioactive Compounds. Phytother. Res. 2008; 22, 709-24.

28. Rupasinghe, H. P., Jackson, C. J., Poysa, V., Berardo, C. D., Bewley, J. D. and Jenkinson, J. (2003). Soyasapogenol A and B distribution in soybean, (Glycine max L. Merr.) in relation to seed physiology, genetic variability and growing location. Journal of Agricultural Food Chemistry. 51,20, pp.5888-5894.

29. Liu F; Kim J; Li Y; Liu X; Li J; Chen X, (2001). An Extract of Lagerstroemia speciosa L. Has Insulin-Like Glucose Uptake-Stimulatory and Adipocyte Differentiation-Inhibitory Activities in 3T3-L1 Cells. J Nutr. 131(9), 2242- 2247. 